Original paper

\title{
Role of quantitative hepatitis B surface antigen levels in predicting liver biopsy time in treatment-naive chronic hepatitis B patients
}

\author{
Bengü Tatar, Ayse Acar, Pelın Adar, Sukran Kose \\ Department of Infectious Diseases and Clinical Microbiology, University of Health Sciences, Izmir Tepecik Education and Research Hospital, Turkey
}

\begin{abstract}
Aim of the study: The quantitative hepatitis B surface antigen (qHBsAg) level indicates the amount of transcriptional activity of covalently closed circular DNA (cccDNA) and integrated DNA in hepatocytes which plays a role in development of chronic hepatitis B (CHB) and may help decide whether the treatment is necessary or not. The aim of this study is to evaluate the association between serum qHBsAg levels and viral replication and stage of liver fibrosis in treatment-naive CHB patients and to determine the role of qHBsAg levels in predicting when liver biopsy is necessary.
\end{abstract}

Material and methods: 967 patients were included in the study. Because of refusal of liver biopsy the study was conducted on 123 patients. The association between qHBsAg levels with HBV DNA, $\alpha$-fetoprotein, fibrosis stage and histology activity index was evaluated.

Results: Of the patients, mean age was $48 \pm 11.2$ years and $56.1 \%$ were male. We found that patients with HBV $\mathrm{DNA} \geqslant 2000 \mathrm{lU} / \mathrm{ml}$ had a higher qHBsAg titer in comparison with HBV DNA $<2000 \mathrm{lU} / \mathrm{ml}$. However, there was no relationship between qHBsAg titer and liver necroinflammation or fibrosis stage.

Conclusions: Monitoring of qHBsAg together with HBV DNA may be helpful in CHB management. However, qHBsAg level does not provide knowledge about the timing of biopsy or the decision of $\mathrm{CHB}$ treatment.

Key words: chronic hepatitis B, quantitative hepatitis B surface antigen, liver biopsy, hepatocytes.

\section{Address for correspondence}

Bengü Tatar, Department of Infectious Diseases and Clinical Microbiology, University of Health Sciences, Izmir Tepecik Education and Research Hospital, Turkey, e-mail: b.gtatar@hotmail.com

\section{Introduction}

There are approximately 240 million chronic hepatitis B (CHB) surface antigen (HBsAg) carriers worldwide and it represents a wide spectrum ranging from inactive infection to progressive $\mathrm{CHB}$ which leads to cirrhosis and hepatocellular carcinoma (HCC). In addition, $\mathrm{HBeAg}$-negative $\mathrm{CHB}$ incidence is increasing and constitutes the majority of cases in most countries [1-3].

Initiation of treatment is based on serum HBV DNA, aminotransferase levels and stage of liver necroinflammatory or fibrosis. Also age, family history of HCC or cirrhosis and extrahepatic symptoms should be taken into consideration. However, current guidelines recommend treating patients only with moderate or severe liv- er disease [4]. Early treatment is extremely important so these patients should be monitored $[1,2,5,6]$.

HBV DNA may indirectly reflect the immunological control of HBV infection regardless of viral load. HBsAg is secreted into the circulation by HBV-infected hepatocytes as tubular forms or spherical particles and quantitative hepatitis B surface antigen (qHBsAg) level indicates the amount of transcriptional activity of covalently closed circular DNA (cccDNA) and integrated DNA in hepatocytes [7]. In patients with advanced fibrosis, a decrease in the amount of hepatocytes affects the quantification of HBsAg in serum [8].

Previous studies concluded that qHBsAg is correlated with HBV DNA levels in $\mathrm{HBeAg-positive} \mathrm{pa-}$ tients contrary to HBeAg-negative patients $[9,10]$. 
Liver biopsy is the gold standard in evaluation of fibrosis and management of patients with $\mathrm{CHB}$ but this invasive procedure may increase the risk of complications [11]. During follow-up qHBsAg measurement may help decide whether the treatment is necessary or not. The aim of this retrospective, cross-sectional, single-centre study is to evaluate the association between serum qHBsAg levels and viral replication and stage of liver fibrosis in treatment-naive $\mathrm{CHB}$ patients and to determine the role of qHBsAg levels in predicting when liver biopsy is necessary.

\section{Material and methods}

\section{Patient selection}

This study was performed on 967 patients with CHB infection, who were admitted to the infectious diseases and clinical microbiology outpatient clinic between 2000 and 2018. However, 844 patients refused liver biopsy and therefore the study was conducted on 123 patients. Patients with HBsAg positivity in serum for more than 6 months, who underwent liver biopsy and whose $\mathrm{HBeAg}$ status and HBsAg quantitative level was known were included in the study. Patients with nonalcoholic fatty liver disease, autoimmune hepatitis, chronic hepatitis C co-infection, hepatitis D virus superinfection or HIV co-infection, aged below 16 years and receiving $\mathrm{CHB}$ therapy were excluded.

The patients were divided into two groups according to the median HBV DNA level $<2000 \mathrm{IU} / \mathrm{ml}$ and $\geq 2000 \mathrm{IU} / \mathrm{ml}$.

According to the Ishak scoring system, liver fibrosis and necroinflammation was classified as $\leq 2$ and $>2$ and $\leq 6$ and $>6$ respectively.

\section{Laboratory assessments}

Laboratory data were collected simultaneously with liver biopsy. HBsAg, HBeAg, anti-HBe, anti-HBcIgG, anti-HBs, anti-HCV and anti-HDV were measured by ELISA (Liaison, Diasorin, Italy). Serum qHBsAg was quantified using the Abbott ARCHITECT assay (Abbott Diagnostics, Germany; dynamic range, 0.05-250.0 $\mathrm{IU} / \mathrm{ml})$. HBV DNA levels were measured by real-time polymerase chain reaction (PCR) (COBAS Ampli Prep/COBAS, TaqMan; lower limit of quantification, $20 \mu \mathrm{l} / \mathrm{ml}$ ). HBV DNA levels were classified as $<2000$ $\mathrm{IU} / \mathrm{ml}$ and $\geq 2000 \mathrm{IU} / \mathrm{ml}$. Alanine aminotransferase (ALT), aspartate aminotransferase (AST), total bilirubin (Tbil), and direct bilirubine (Dbil) were analyzed by an AU5800 auto-analyzer (Beckman Coulter Inc. CA, USA). Alpha-fetoprotein (AFP) was analyzed by the DxI 800 auto-analyzer (Beckman Coulter Inc., CA, USA). Prothrombin time (PT) was measured by a CS2500 automated coagulation analyzer (Sysmex Corporation, Kobe, Japan). International normalized ratio (INR) was calculated using INR = patient $\mathrm{PT} /$ mean normal PT formula. Platelets (PLT) were analyzed by a Beckman Coulter LH 780 (Beckman Coulter Ireland Inc., Mervue, Galway, Ireland). The body mass index (BMI) characterized the relative proportion between the weight and the height squared.

A written informed consent form was signed by all patients before biopsy. The Ishak scoring system was used to determine the liver inflammation and fibrosis stages. Fibrosis stage and histology activity index (HAI) were classified as $\leq 2$ and $>2, \leq 6$ and $>6$ respectively.

\section{Statistical analysis}

Statistical analyses were performed using SPSS Version 23. Compliance with normal distribution was examined by the Shapiro-Wilk test. The Mann-Whitney $U$ test was used to compare the data that did not show normal distribution. The $\chi^{2}$ test was used to examine categorical variables. Correlations between two continuous variables were analyzed using Spearman's rank test. The quantitative data were presented as median (min-max) and the qualitative data as a percentage. A $p$ value $<0.05$ was considered significant.

\section{Results}

A total of 123 patients were enrolled in this study: 119 patients were $\mathrm{HBeAg}$-negative and four were $\mathrm{HBeAg}$-positive. AntiHBe positivity was 96.7\% $(119 / 123)$. Fibrosis was grouped as $\leq 2$ and $>2$, necroinflammation was grouped as $\leq 6$ and $>6$. The mean age of the patients was $48 \pm 11.2$ years (range 19-70 years), and 56.1\% (69/123) were male. Demographics and laboratory tests are presented in Table 1.

Between HBV DNA level groups (DNA $\geq 2000 \mathrm{IU} / \mathrm{ml}$ $(n=59)$ and $<2000 \mathrm{IU} / \mathrm{ml}(n=64))$, BMI, AFP, INR, ALT, total bilirubin, albumin and PLT levels were not significantly different (Table 2). But qHBsAg titer was higher and age was younger (39 vs. 47 years; $p=0.003$ ) in patients with $\mathrm{DNA} \geq 2000 \mathrm{IU} / \mathrm{ml}$. Correlation analysis indicated a positive correlation between HBsAg titer and HBV DNA $(r=0.330, p=0.001)$. However, there was no statistically significant correlation between qHBsAg titer and stage of liver necroinflammation or fibrosis (Table 3). Neither fibrosis stage (both fibrosis $\geq 2$ and $<2$ ) nor HAI index (both HAI $\geq 6$ and $<6$ ) was associated with BMI, PT, INR, PLT, 
AFP, ALT and qHBsAg titer. Unlike these results, serum albumin levels were lower in the fibrosis $\geq 2$ group ( 4.4 vs. $4.3 \mathrm{mg} / \mathrm{dl} ; p=0.034$ ). The mean HBsAg titer was 3321.8 and 3270.6 in patients with fibrosis $\geq 2$ and $<2$ respectively $(p=0.821)$. Comparing fibrosis score $\geq 2$ and fibrosis score $<2$ in patients whose HBV DNA levels were $<2000 \mathrm{IU} / \mathrm{ml}$ there was no statistically significance between $\mathrm{qHBsAg}$ and fibrosis (2609.5 vs. $1739.69 ; p=0.587)$.

\section{Discussion}

In this study, HBV DNA levels, fibrosis and HAI were compared to evaluate the availability of qHBsAg titer in patients with $\mathrm{CHB}$ infection. The virological and biochemical values of the groups were compared according to HBV DNA levels. While there was a weak positive correlation between HBsAg titer and HBV DNA ( $r=0.303, p=0.001)$, no association was observed between HAI, fibrosis or AFP. However, the results of our study are different from some previous studies. In a European study, $226 \mathrm{HBV}$ monoinfected patients who did not receive antiviral therapy were analyzed according to different phases of HBV infection. It was found that serum HBsAg levels had a strong correlation with HBV DNA levels $(r=0.79, p<0.01)$ and HBeAg-positive patients had higher serum HBsAg levels than HBeAg-negative patients [10].

The study of $\mathrm{Li}$ et al. evaluated $505 \mathrm{CHB}$ patients (333 were $\mathrm{HBeAg}$-positive and 172 were $\mathrm{HBeAg-neg-}$ ative). In $\mathrm{HBeAg}$-positive patients they reported
Table 1. Demographic, virological and biochemical parameters of patients

\begin{tabular}{|c|c|c|c|c|}
\hline Parameters & Mean $\pm S D$ & Median & Min & Max \\
\hline Age (year) & $42.8 \pm 11.2$ & 41.0 & 19.0 & 70.0 \\
\hline BMI $\left(\mathrm{kg} / \mathrm{m}^{2}\right)$ & $26.0 \pm 4.8$ & 25.2 & 16.1 & 42.2 \\
\hline qHBsAg (IU/ml) & $4625.9 \pm 5614.9$ & 3312.8 & 19.0 & 38694.6 \\
\hline HBV DNA (IU/ml) & $11377.6 \pm 25598.4$ & 2755.0 & 29.9 & 169000.0 \\
\hline $\operatorname{AFP}(\mu \mathrm{g} / \mathrm{l})$ & $2.2 \pm 1.6$ & 1.8 & 0.6 & 9.4 \\
\hline INR & $3.8 \pm 4.6$ & 1.0 & 0.0 & 14.4 \\
\hline PT (s) & $8.7 \pm 5.6$ & 10.5 & 0.1 & 25.4 \\
\hline ALT (U/I) & $24.3 \pm 17.6$ & 20.0 & 7.0 & 170.0 \\
\hline AST (U/l) & $24.7 \pm 9.9$ & 23.0 & 9.0 & 75.0 \\
\hline Tbil (mg/dl) & $0.8 \pm 0.3$ & 0.7 & 0.6 & 1.9 \\
\hline Dbil (mg/dl) & $0.4 \pm 1.5$ & 0.1 & 0.0 & 11.5 \\
\hline Albumin $(\mathrm{g} / \mathrm{l})$ & $4.4 \pm 0.3$ & 4.4 & 3.6 & 5.0 \\
\hline $\operatorname{PLT}\left(\times 10^{3} / \mu \mathrm{l}\right)$ & $244.0 \pm 59.2$ & 236.0 & 112.0 & 429.0 \\
\hline HAl (Ishak) & $5.3 \pm 1.6$ & 5.0 & 0.0 & 12.0 \\
\hline F (Ishak) & $1.4 \pm 1.1$ & 1.0 & 0.0 & 5.0 \\
\hline
\end{tabular}

$B M I$ - body mass index, qHBsAg - quantitative hepatitis $B$ surface antigen, HBV DNA - hepatitis B virus deoxyribonucleic acid, AFP - $\alpha$-fetoprotein, INR - international normalized ratio, PT - prothrombin time, ALT - alanine aminotransferase, AST - aspartate aminotransferase, Tbil - total bilirubin, Dbil - direct bilirubin, PLT - platelets, $\mathrm{HAl}$ - histology activity index, F- fibrosis

a strong correlation between HBsAg levels and METAVIR fibrosis scores $(r=-0.50, p<0.001)$ and HBV DNA levels $(r=0.60, p<0.001)$; however, unlike these results, no correlation was observed in HBeAg-negative patients $(r=0.09, p=0.239, r=0.12, p=0.123$

Table 2. Biochemical and virological characteristics of two groups classified according to HBV DNA levels

\begin{tabular}{|c|c|c|c|}
\hline Parameters & $\begin{array}{c}\text { HBV DNA }(\mathrm{IU} / \mathrm{ml})<2000^{*} \\
(n=59)\end{array}$ & $\begin{array}{c}\text { HBV DNA }(\mathrm{IU} / \mathrm{ml}) \geqslant 2000 * \\
(n=64)\end{array}$ & $p^{* *}$ \\
\hline Age (years) & $47(24-65)$ & $39(19-70)$ & 0.003 \\
\hline BMI $\left(\mathrm{kg} / \mathrm{m}^{2}\right)$ & $24.6(18.4-36.3)$ & $25.8(16.1-42.2)$ & 0.122 \\
\hline qHBsAg (IU/ml) & $2567.8(19.0-18303.6)$ & 4217.5 (713.3-38694.6) & 0.001 \\
\hline $\operatorname{AFP}(\mu \mathrm{g} / \mathrm{l})$ & $1.9(0.6-9.4)$ & $1.6(0.6-7.8)$ & 0.11 \\
\hline INR & $1.1(0-11.8)$ & $1.0(0.8-14.4)$ & 0.31 \\
\hline PT (s) & $10.3(0.1-22)$ & $10.9(0.1-25.4)$ & 0.47 \\
\hline ALT (U/I) & $20(7-60)$ & $21(7-79)$ & 0.27 \\
\hline Tbil (mg/dl) & $0.6(0.1-1.8)$ & $0.7(0.3-1.9)$ & 0.89 \\
\hline Dbil (mg/dl) & $0.1(0.0-0.9)$ & $0.1(0.1-10.8)$ & 0.44 \\
\hline Albumin (g/l) & $4.3(3.6-5)$ & $4.4(3.6-4.9)$ & 0.20 \\
\hline 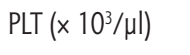 & 231 (129-371) & $248(112-429)$ & 0.28 \\
\hline HAl (Ishak) & $5.3 \pm 1.7$ & $5.4 \pm 1.6$ & 0.92 \\
\hline F (Ishak) & $1.5 \pm 1.2$ & $1.4 \pm 1.0$ & 0.42 \\
\hline
\end{tabular}

$n$ - number of patients, BMI - body mass index, qHBsAg - quantitative hepatitis B surface antigen, HBV DNA - hepatitis B virus deoxyribonucleic acid, AFP - $\alpha$-fetoprotein INR - international normalized ratio, PT - prothrombin time, ALT - alanine aminotransferase, AST - aspartate aminotransferase, Tbil - total bilirubin, Dbil - direct bilirubin, PLT - platelet, *median (min-max), * *Mann-Whitney U test 
Table 3. Correlation analysis of quantitative HBsAg with HBV DNA, HAI, F and AFP

\begin{tabular}{ll}
\hline Parameters & qHBsAg $(\mathrm{IU} / \mathrm{ml})$ \\
\hline HBV DNA $(\mathrm{IU} / \mathrm{ml})$ & $r=0.303, p=0.001$ \\
\hline HAl $(\mathrm{lshak})$ & $r=0.003, p=0.975$ \\
\hline AFP $(\mu \mathrm{g} / \mathrm{l})$ & $r=-0.095, p=0.303$ \\
\hline F (lshak) & $r=-0.036, p=0.699$ \\
\hline
\end{tabular}

$r$-Spearman's rank test, qHBSAg - quantitative hepatitis B surface antigen, HBV DNA hepatitis B virus deoxyribonucleic acid, HAl - histology activity index,

AFP - $\alpha$-fetoprotein, $F$ - fibrosis

respectively) [12]. Wang et al. studied comparison of HBsAg levels and HBeAg levels in $203 \mathrm{HBeAg}$-positive $\mathrm{CHB}$ patients with histologic stage and they found that serum HBsAg levels were negatively correlated with fibrosis stage $(r=-0.56, p=0.001)$ and necroinflammation $(r=-0.39, p=0.001)$ [13]. The majority of our patients are $\mathrm{HBeAg}$-negative patients, which may be an explanation for this difference.

In our study, two groups were compared according to HBV DNA level (DNA $\geq 2000 \mathrm{IU} / \mathrm{ml}$ and $<2000$ $\mathrm{IU} / \mathrm{ml})$; median value of $\mathrm{qHBsAg}$ titer $(p=0.001)$ and median age $(p=0.003)$ were significantly different between these groups. HBsAg titer was higher in the HBV DNA $\geq 2000 \mathrm{IU} / \mathrm{ml}$ group than the $<2000 \mathrm{IU} / \mathrm{ml}$ group. No significant difference was found between BMI, AFP, INR, ALT, Tbil, albumin and PLT median values and HBV DNA levels. These results were similar to the results of previous studies. In a study from our country performed by Günal et al., which evaluated the association between serum quantitative HBsAg, ALT and HBV DNA levels in HBeAg-negative $\mathrm{CHB}$ infection, patients were divided into two groups according to HBV DNA levels, > $2000 \mathrm{IU} / \mathrm{ml}$ (50/99) and $<2000 \mathrm{IU} / \mathrm{ml}$ (49/99), and comparison between quantitative HBsAg levels and ALT, HBV DNA was performed. They reported a weak significant correlation between HBV DNA and serum qHBsAg levels $(r=0.503, p=0.0001)$, and a weak but statistically significant correlation between HBsAg and ALT levels $(r=0.283, p=0.005)$ [14]. Balkan et al. studied the correlation of qHBsAg levels between ALT, HBV DNA, HAI severity and fibrosis in $104 \mathrm{HBeAg-nega-}$ tive hepatitis $\mathrm{B}$ infection and $38 \mathrm{HBeAg}$-positive and $62 \mathrm{HBeAg}$-negative CHB patients. In HBeAg-positive $\mathrm{CHB}$ patients, a moderate positive correlation was detected between serum qHBsAg level and HBV DNA, but no correlation was found between the serum qHBsAg level and ALT, HAI severity or the fibrosis stage. In HBeAg-negative hepatitis B infection and HBeAg-negative $\mathrm{CHB}$ group no correlation was reported between serum qHBsAg level, ALT, HAI, and fibrosis [15].

According to liver histopathology, HAI was classified as $\geq 6$ and $<6$ and fibrosis was classified as $\geq 2$ and $<2$ and no statistically significant difference was found between groups compared to qHBsAg titer. Seto et al. evaluated HBsAg in the assessment of liver histology in $140 \mathrm{HBeAg}$-positive patients. They found an inverse correlation between HBsAg levels and degree of fibrosis; compared to patients with fibrosis $>1$, patients with fibrosis $\leq 1$ had significantly higher median HBsAg levels (50320 and $7820 \mathrm{IU} / \mathrm{ml}$, respectively, $p<0.001)$ [16]. Similarly, the diagnostic value of qHBsAg was studied by Xun et al. in 197 treatment naive HBeAg-positive CHB infected patients with fibrosis $\geq 2$, which was defined as significant fibrosis. They found a stronger inverse correlation between $\mathrm{qHBsAg}$

Table 4. Characteristics of groups according to fibrosis and HAl

\begin{tabular}{lcccccc}
\hline \multicolumn{2}{c}{ Fibrosis } & \multicolumn{3}{c}{ HAI } \\
\hline Parameters & $<2^{*}$ & $\geqslant 2^{*}$ & $p^{* *}$ & $<6^{*}$ & $\geqslant 6^{*}$ & $p^{* *}$ \\
\hline BMI $\left(\mathrm{kg} / \mathrm{m}^{2}\right)$ & $25.3(16.1-42.2)$ & $25.2(18.4-31.3)$ & 0.58 & $24.9(16.1-42.2)$ & $25.5(21.6-31.3)$ & 0.59 \\
\hline PT $(\mathrm{s})$ & $10.7(0.1-25.4)$ & $10.4(0.6-16.3)$ & 0.24 & $10.9(0.1-25.4)$ & $10.5(0.1-16.3)$ & 0.31 \\
\hline INR & $1.0(0-14.4)$ & $1.1(0.1-12.6)$ & 0.06 & $1.01(0-14.4)$ & $1.1(0.1-11.8)$ & 0.10 \\
\hline Albumin $(\mathrm{g} / \mathrm{l})$ & $4.4(4-4.9)$ & $4.3(3.6-5)$ & 0.03 & $4.4(3.6-4.9)$ & $4.4(3.6-5)$ & 0.74 \\
\hline PLT $(\times 10-3 / \mu \mathrm{l})$ & $231(139-412)$ & $241(112-429)$ & 0.38 & $224(129-412)$ & $257(112-429)$ & 0.008 \\
\hline AFP $(\mu \mathrm{g} / \mathrm{l})$ & $1.7(0.6-9.4)$ & $1.8(0.7-5.3)$ & 0.63 & $1.8(0.7-9.4)$ & $1.7(0.6-9.1)$ & 0.10 \\
\hline ALT $(\mathrm{U} / \mathrm{l})$ & $21.5(10-170)$ & $19(7-79)$ & 0.10 & $20(9-170)$ & $21.5(7-79)$ & 0.70 \\
\hline qHBsAg $(\mathrm{IU} / \mathrm{ml})$ & $3322(50.7-38694.6)$ & $3271(19.04-31186.9)$ & 0.82 & $3312(50.7-38694.6)$ & $3313(19.0-25091)$ & 0.97 \\
\hline HBV DNA $(\mathrm{IL} / \mathrm{ml})$ & $3000(30-169.000)$ & $1750(42-72.600)$ & 0.40 & $1945(30-169.000)$ & $2960(42-72.600)$ & 0.95 \\
\hline
\end{tabular}

HAI - histology activity index, BMI - body mass index, PT - prothrombin time, INR - international normalized ratio, PLT - platelets, AFP - $\alpha$-fetoprotein, ALT - alanine aminotransferase, qHBSAg - quantitative hepatitis B surface antigen, HBV DNA - hepatitis B virus deoxyribonucleic acid, "median (min-max), **Mann-Whitney U test 
and fibrosis $(r=-0.533, p<0.001)$ than that of HBV DNA and fibrosis $(r=-0.399, p<0.001)$ [17].

This study has several limitations; firstly it is a retrospective study. Secondly, the number of $\mathrm{HBeAg}$-positive patients was inadequate so it is not comparable with $\mathrm{HBeAg}$-negative patients; previous reports have shown that qHBsAg is correlated with $\mathrm{HBV}$ DNA levels in $\mathrm{HBeAg}$-positive patients while it is lower in HBeAg-negative patients. Thirdly, although the most prevalent genotype in our country is genotype $\mathrm{D}$, unavailability of HBV genotyping limited the study. Lastly patients could not be classified in groups according to $\mathrm{qHBsAg}$ levels because of similar values.

\section{Conclusions}

Our findings indicate that monitoring of $\mathrm{qHBsAg}$ together with HBV DNA may be helpful in CHB management. However, qHBsAg level does not provide knowledge about either timing of biopsy or decision of $\mathrm{CHB}$ treatment.

\section{Disclosure}

The authors report no conflict of interest.

\section{References}

1. Schweitzer A, Horn J, Mikolajczyk RT, et al. Estimations of worldwide prevalence of chronic hepatitis B virus infection: A systematic review of data published between 1965 and 2013. Lancet 2015; 386: 1546-1555.

2. Lozano R, Naghavi M, Foreman K, et al. Global and regional mortality from 235 causes of death for 20 age groups in 1990 and 2010: A systematic analysis for the Global Burden of Disease Study 2010. Lancet 2012; 380: 2095-2128.

3. Hadziyannis S, Papatheodoridis GV. Hepatitis B e antigen-negative chronic hepatitis: natural history and treatment. Semin Liver Dis 2006; 26: 130-141.

4. EASL 2017 Clinical Practice Guidelines on the management of hepatitis B virus infection. Easl J Hepatol 2017; 67: 370-398.

5. Ott JJ, Stevens GA, Groeger J, et al. Global epidemiology of hepatitis B virus infection: New estimates of age-specific HBsAg seroprevalence and endemicity. Vaccine 2012; 30: 2212-2219.

6. Cornberg M, Wong VW, Locarnini S, et al. The role of quantitative hepatitis B surface antigen revisited. J Hepatol 2017; 66: 398-411.

7. Chan HL, Wong VW, Tse AM, et al. Serum hepatitis B surface antigen quantitation can reflect hepatitis B virus in the liver and predict treatment response. Clin Gastroenterol Hepatol 2007; 5: $1462-1468$.

8. Mei-Zhu Hong, Wen-Qi Huang, Feng Min F, et al. Enhanced HBsAg synthesis correlates with increased severity of fibrosis in chronic hepatitis B patients. PLoS One 2014; 9: e87344.

9. Manesis EK, Papatheodoridis GV, Tiniakos DG, et al. Hepatitis $B$ surface antigen: relation to hepatitis $B$ replication parameters in HBeAg-negative chronic hepatitis B. J Hepatol 2011; 55: 61-68.
10. Jaroszewicz J, Calle Serrano B, Wursthorn K, et al. Hepatitis B surface antigen (HBsAg) levels in the natural history of hepatitis B virus (HBV)-infection: a European perspective. J Hepatol 2010; 52: 514-522.

11. Piccinino F, Sagnelli E, Pasquale G, et al. Complications following percutaneous liver biopsy. A multicentre retrospective study on 68,276 biopsies. J Hepatol 1986; 2: 165-173.

12. Qiang Li, Weixia Li, Chuan Lu, et al. Serum hepatitis B surface antigen levels predict insignificant fibrosis and non-cirrhosis in hepatitis B e antigen positive patients with normal or mildly elevated alanine transaminase levels. Oncotarget 2017; 8: 8646386470.

13. Wang H, Yan R, Zhou Y, et al. Comparison of hepatitis B surface antigen and e antigen in predicting liver histology in hepatitis $\mathrm{B}$ e antigen-positive chronic hepatitis B patients. Hepatol Int 2014; 8: 216-223.

14. Günal Ö, Barut Ş, Etikan İ, et al. Relation between serum quantitative HBsAg, ALT and HBV DNA levels in HBeAg negative chronic HBV infection. Turk J Gastroenterol 2014; 25: 142-146.

15. Balkan A, Namiduru M, Balkan Y, et al. Are serum quantitative hepatitis B surface antigen levels, liver histopathology and viral loads related in chronic hepatitis B-infected patients? Saudi J Gastroenterol 2016; 22: 208-214.

16. Seto WK, Wong DK, Fung J, et al. High hepatitis B surface antigen levels predict insignificant fibrosis in hepatitis B e antigen positive chronic hepatitis B. PLoS One 2012; 7: e43087.

17. Xun YH, Zang GQ, Guo JC, et al. Serum hepatitis B surface antigen quantification as a useful assessment for significant fibrosis in hepatitis B e antigen-positive hepatitis B virus carriers. J Gastroenterol Hepatol 2013; 28: 1746-1755. 